\title{
Inadequate intakes of dietary zinc among pregnant women from subsistence households in Sidama, Southern Ethiopia
}

\author{
Yewelsew Abebe ${ }^{1}$, Alemtsehay Bogale ${ }^{1}$, K Michael Hambidge $^{2}$, Barbara J Stoecker ${ }^{3}$, \\ Isabel Arbide ${ }^{4}$, Akilu Teshome ${ }^{4}$, Nancy F Krebs ${ }^{2}$, Jamie E Westcott ${ }^{2}$, Karl B Bailey ${ }^{5}$ and \\ Rosalind S Gibson ${ }^{5, *}$ \\ ${ }^{1}$ College of Agriculture, Hawassa University, Awassa, Ethiopia: ${ }^{2}$ Section of Nutrition, Department of Pediatrics, \\ University of Colorado Health Sciences Center, Denver, CO, USA: ${ }^{3}$ Department of Nutrition, Oklahoma State \\ University, Stillwater, OK, USA: ${ }^{4}$ Bushulo Health Center, Awassa, Ethiopia: ${ }^{5}$ Department of Human Nutrition, \\ University of Otago, Dunedin, New Zealand
}

Submitted 10 August 2006: Accepted 17 April 2007: First published online 5 July 2007

\begin{abstract}
Objective: To assess the prevalence of zinc inadequacy based on dietary intakes and plasma zinc concentrations and, simultaneously, the prevalence of inadequate intakes of energy, protein, calcium and iron.

Design: A cross-sectional study of a convenience sample of subsistence farming households in Sidama, Southern Ethiopia.

Subjects: Dietary intakes were calculated from 1-day weighed food records and 40 repeats from 99 pregnant women in the third trimester using analysed values of major staple foods for zinc, iron, calcium and phytate. The distribution of observed intakes was adjusted for usual intakes and the prevalence of inadequacy estimated using the estimated average requirement (EAR) cutpoint method. Prevalence of inadequacy for zinc, protein and iron intakes were compared with those based on biochemical measures.

Results: Prevalence of zinc inadequacy was very high: 99\% for US FNB EAR and $100 \%$ for IZiNCG EAR compared to $72 \%$ based on low plasma zinc concentrations. Corresponding prevalence estimates for iron were much lower: $4 \%$ for inadequate intakes based on US FNB EAR vs. $8.7 \%$ for iron deficiency anaemia (haemoglobin $<110 \mathrm{gl}^{-1}$; ferritin $<12 \mu \mathrm{gl}^{-1}$ ) and $32.3 \%$ for low storage iron. Prevalence of inadequacy for protein was 100\% for adjusted intakes and $91 \%$ for serum albumin $<32 \mathrm{gl}^{-1}$. For calcium, $74 \%$ were at risk for inadequate intakes. Conclusion: The high prevalence of inadequate intakes of zinc and protein was reasonably consistent with those based on biochemical measures. Such dietary deficits could be overcome by regular consumption of cellular animal protein. In contrast, both dietary and biochemical measures of iron inadequacy were low.
\end{abstract}

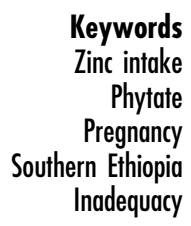

Inadequate intakes of dietary zinc have been identified as a major factor in the aetiology of zinc deficiency in developing countries ${ }^{1}$. Such inadequacies may arise from low intakes of zinc per se and/or poor bioavailability of dietary zinc. However, quantitative data on zinc intakes of population groups in developing countries at risk to zinc deficiency are limited, in part because of the paucity of data on the zinc content of indigenous staple foods. Substitution of zinc values for staple foods grown in Western countries is not advisable because the zinc content of plant-based foods tends to reflect local soil zinc levels ${ }^{2,3}$.

Poor bioavailability of dietary zinc is associated with plant-based diets high in phytate, a potent inhibitor of zinc absorption ${ }^{4}$. Phytate forms insoluble complexes in the gastrointestinal tract with zinc; these complexes cannot be digested or absorbed because of the absence of intestinal phytase enzyme in humans 5 . Indeed, the relative bioavailability of zinc depends mainly on the phytate : zn ratio of the diet ${ }^{1}$.

Certain household food preparation and processing practices (e.g. fermentation, germination and soaking) can reduce the phytate content of plant foods ${ }^{6}$, and thus may lead to some improvement in the bioavailability of zinc from plant-based diets. This reduction may be important in diets consumed in Southern Ethiopia, where two of the major dietary staples consumed - starchy foods based on enset (Enset ventricosum) and enjera prepared from teff (Eragrotis teff) - are fermented.

During pregnancy, zinc requirements are especially high because zinc is essential for growth and development of 
the foetus and maternal tissue accretion ${ }^{7}$. Whether the dietary zinc intakes of women in rural Southern Ethiopia are sufficient to meet these high requirements during pregnancy has not yet been established. Zinc deficiency has been associated with adverse effects on both maternal health and pregnancy outcome in some studies, specifically pregnancy complications, reduced birth weight and congenital anomalies ${ }^{8-10}$.

In light of the plant-based diets consumed by subsistence farming households in rural Southern Ethiopia, we hypothesised that pregnant women may be especially at risk of inadequate intakes of dietary zinc. To our knowledge, however, there have been no community-based studies focusing on the zinc status of pregnant Ethiopian women. Therefore, the current study aimed to (1) quantify the zinc and phytate intakes, and the phytate: $\mathrm{Zn}$ molar ratios of the diets of a self-selected group of subsistence pregnant women living in Sidama province, Southern Ethiopia and (2) examine the relationship between the prevalence of inadequate zinc intakes and low plasma zinc concentrations. In addition, the adequacy of the dietary intakes of energy, protein, calcium and iron was also assessed.

\section{Methods}

\section{Participants}

The subjects of this cross-sectional study were a convenience sample of women aged 27.8 \pm 4.6 years (mean \pm standard deviation, SD) from subsistence farming households living in three rural communities (Alamura, Kurda and Fincawoa) located in Sidama zone in the Rift Valley lowlands of Southern Ethiopia. All the women were in the third trimester of pregnancy, based on an assessment of fundal height (Table 1) performed by nurses from the prenatal outreach programme of the nearby Busholo Health Center. The study was conducted during the rainy season in July 2004.

Verbal consent was obtained from all the participants after the nature of the study had been fully explained to

Table 1 Selected demographic, anthropometric and some household food security characteristics of subsistence pregnant women $(n=99)$ from Sidama

\begin{tabular}{lc}
\hline & Mean (SD) or \% \\
\hline Age (years) & $27.8(4.6)$ \\
Fundal height (cm) & $7.1(1.0)$ \\
No schooling (\%) & 76.8 \\
Gravida: three or less (\%) & 48.0 \\
Gravida: four to six (\%) & 36.7 \\
Gravida: seven to eleven (\%) & 15.3 \\
Weight $(\mathrm{kg})$ & $52.1(6.1)$ \\
Height $(\mathrm{cm})$ & $154.8(6.5)$ \\
HAZ & $-1.48(1.1)$ \\
BMI (kg m & -2 ) \\
Rarely had enough food to eat (\%) & $21.7(2.0)$ \\
Sometimes or rarely had enough food to eat (\%) & 37.4 \\
& 98.0
\end{tabular}

SD - standard deviation; HAZ - height-for-age Z-score; BMI - body mass index. them, and witnessed by a local health worker or community leader. The study protocol was approved by the Human Ethics Committee of Debub University, Awassa, Ethiopia, and the COMIRB of the University of Colorado, Denver, USA.

Data on sociodemographic characteristics were collected through personal interviews and observations using a pretested questionnaire. All interviews were conducted by trained research assistants who were fluent in both the local language (Sidamigno) and Amharic, and had a good understanding of English. Weight and height of each respondent were measured at the beginning of the survey using standardised techniques and calibrated equipment ${ }^{11}$, with the subjects wearing light clothing and no shoes.

\section{Assessment of dietary intakes}

Trained research assistants fluent in the local language collected 1-day weighed food records from each of the women in the household. Weekend days and weekdays were proportionately represented in the final survey to account for any day-of-the-week effects on food and/or nutrient intake. Foods and beverages consumed by the women were weighed using digital scales ( $2 \mathrm{~kg}$ maximum weight, model CS 2000; Ohaus Corporation) accurate to $\pm 1 \mathrm{~g}$. Detailed weighed recipe data were also collected for all the composite dishes consumed on the survey day and used to calculate the weight of the actual ingredients consumed by the respondent, as described by Gibson and Ferguson ${ }^{12}$. Average recipe data were compiled for use when actual recipe data were not available. Women were instructed not to change their normal dietary pattern over the food record day. In addition, duplicate 1-day weighed food records were collected on a second nonconsecutive day from a randomly selected sub-sample ( $n=40)$ of the respondents.

A food composition database was compiled to compute the energy and selected nutrient intakes based on the food composition tables for use in Ethiopia ${ }^{13,14}$. Additionally, some literature values ${ }^{15}$ and analysed calcium, zinc, iron and phytate values for representative staple foods collected from the households and local markets ${ }^{16}$ were also used. Crude fibre values in the Ethiopian food composition tables were replaced by total dietary fibre values from the World Food Dietary Assessment System ${ }^{17}$. Median (1st and 3rd quartile) intakes (per day; per MJ) and the major food sources of energy, nutrients, dietary fibre and phytate were calculated from the coded 1-day weighed food records. Foods and beverages were classified into eight major food groups.

Observed energy intakes were adjusted for digestibility by $0.95^{18}$ and protein intakes for digestibility and amino acid score by $0.68^{19,20}$ to take into account the high intakes of dietary fibre and the very low content of animal-source foods in the diets of the study participants 
in Sidama, Southern Ethiopia. Iron intakes were not adjusted for the enhancing effects of either ascorbic acid or cellular animal protein because intakes of these were either very low or non-existent.

\section{Assessment of the prevalence of low biochemical indices of zinc, iron and protein status}

Non-fasting morning venepuncture blood samples were collected from the participants in the sitting position during clinics held in the open-air Alamura community center. Blood was drawn using syringes (BectonDickenson), and then transferred into trace-element-free heparinised Eppendorf tubes (Biorad), which were stored in a cooler. One aliquot of this freshly collected anticoagulated whole blood was used for a complete blood cell count performed by an electronic counter in the nearby Bushulo Health Center. A second aliquot was separated within $2 \mathrm{~h}$ using trace-element-free techniques based on the recommended procedures of the International Zinc Nutrition Consultative Group (IZiNCG) ${ }^{1}$, and the plasma stored frozen at $-20^{\circ} \mathrm{C}$ in trace-element-free polypropylene vials. The frozen plasma samples were hand-carried by K.M.H. to the University of Colorado Health Science Center for analysis. Plasma zinc was analysed by flame atomic absorption spectrophotometry, as described elsewhere ${ }^{21}$. Plasma ferritin and C-reactive protein (CRP) were assayed by nepholometry (Dade Behring BNII Automated Nepholometer) at the General Clinical Research Center, Denver, CO, and plasma albumin by spectrophotometry. Plasma CRP was used to indicate the presence of infection or inflammation ${ }^{22}$. Women with elevated plasma CRP (i.e. $\geq 5 \mathrm{mgl}^{-1}$ ) were excluded from the statistical analyses.

The precision and accuracy of all the biochemical assays were checked using appropriate manufacturer's controls or a certified reference material for zinc (Bovine Serum Reference Material \#1590; National Institute of Standards and Technology). For plasma ferritin, CRP and albumin, values for the manufacturer's controls fell within the certified ranges. Coefficients of variation (CV) for the low, medium or high controls for serum ferritin were $8.6 \%, 3.1 \%$ and $4.0 \%$, and $4.1 \%, 7.1 \%$ and $5.6 \%$ for CRP, respectively. For plasma albumin, the CV for the low and high controls (Liquichex; Biorad) were $0.8 \%$ and 1.0\%, respectively. For plasma zinc, the mean value (SD, CV\%) was 13.66 (1.9, 2.1\%) compared with the certified value of $13.62(6.0,6.7 \%) \mu \mathrm{moll}^{-1}$.

The prevalence of zinc deficiency (in the absence of infection or inflammation) was defined by the IZiNCG cutoff values for plasma zinc for women in the third trimester of pregnancy ${ }^{1}$. Likewise, for iron deficiency anaemia, a combination of low haemoglobin $\left(<110 \mathrm{~g}^{-1}\right)^{23}$ and low plasma ferritin concentrations (i.e. $\left.<12 \mu \mathrm{gl}^{-1}\right)^{24}$ in the absence of infection or inflammation was used. This same cutoff value for plasma ferritin was used to indicate the prevalence of low iron stores.

\section{Statistical analysis}

Statistical analyses were carried out using SPSS version 8.0 (SPSS Inc.). All variables were tested for normality using the Kolmogorov-Smirnov test. Dietary results are expressed in terms of the median and interquartile range because the intakes of several nutrients were not normally distributed. Correlations between dietary intake measures were examined using Spearman's rank correlation test.

Before assessing the prevalence of inadequate intakes, the observed distributions of 1-day intakes were adjusted to remove the variability introduced by day-to-day variation in nutrient intakes within an individual (i.e. to remove the within-subject variation). This adjustment was achieved by using the nutrient intake data from the 40 repeated 1-day food records and the computer program PC-Side ${ }^{25}$.

Estimates of the prevalence of inadequate intakes for zinc, protein, calcium and iron were calculated using the estimated average requirement (EAR) cutpoint method ${ }^{26}$ using estimates of the average requirements for each nutrient of interest and the 'usual intake' distributions from PC-Side. For zinc, the EARs for pregnancy set by the US Food and Nutrition Board (FNB) ${ }^{7}$ and by IZiNCG $^{1}$ were used. For protein and calcium, estimates of the mean requirements for pregnancy compiled by Bunch and Murphy ${ }^{17}$, and based on those set by international agencies, were used ${ }^{19,27}$. For iron, the EAR for pregnancy set by the US $\mathrm{FNB}^{7}$ was applied because an EAR for iron has not been given in the revised Food and Agriculture Organization of the United Nations (FAO)/ World Health Organization (WHO) requirement estimates ${ }^{27}$.

Energy intakes adjusted for digestibility were compared to the revised energy requirement for pregnancy by $\mathrm{FAO}^{18}$. The average energy requirement of the group was calculated from the mean basal metabolic rate (BMR) multiplied by the average physical activity level (PAL). The BMR was predicted from standard age- and sexspecific equations based on the mean body weight of the women in the third trimester of pregnancy adjusted for prepregnant weight by assuming an average gestational weight gain of $12 \mathrm{~kg}$. A value for habitual PAL (mid-point of the moderately active lifestyle) was used for this group of subsistence farmers, as recommended by $\mathrm{FAO}^{18}$. An additional $2.0 \mathrm{MJ} \mathrm{day}^{-1}$ was added to take into account the additional energy cost of the third trimester of pregnancy $^{18}$.

\section{Results}

\section{Characteristics of study population}

The characteristics of the study population are shown in Table 1 . The self-reported age (mean \pm SD) of the women was $27.8 \pm 4.6$ years. All the women were subsistence farmers; $76.8 \%(n=76)$ had no formal education and only $10 \%(n=10)$ had four or more years of schooling. 
Almost all of the women lived in houses made of mud walls with thatched roofs, no windows and a shared latrine.

Of the women, $11.1 \%$ and $4.1 \%$ had a height below 148 and $145 \mathrm{~cm}$, respectively, and 30\% $(n=30)$ were stunted (i.e. height-for-age $Z$-score $(\mathrm{HAZ})<-2 \mathrm{SD}$ ). The number of pregnancies ranged from one to eleven (mean $\pm \mathrm{SD}$; $4.1 \pm 2.5)$. Of the women, $48 \%(n=47)$ had $0-3$ pregnancies, 36.7\% $(n=36)$ had 4-6 pregnancies and 15.3\% $(n=15)$ had $7-11$ pregnancies. In relation to food security, $98 \%$ of the women responded that they only sometimes or rarely had enough to eat, and over $90 \%$ reported they had not eaten meat or fish since the Easter holiday, even though the survey was undertaken in July.

\section{Dietary assessment}

Median (1st, 3rd quartile) dietary intakes (per day and per MJ) are shown in Table 2. Major food sources of energy, protein, zinc, iron and calcium are presented in Table 3. Cereal grains (mainly unrefined maize) contributed the major source of energy, protein, iron and zinc, whereas starchy foods prepared from enset (E. ventricosum) (mainly kocho) were the primary source of calcium and the secondary source of iron. Vegetables (mainly Ethiopian kale, Brassica carinata braun) provided the secondary source of calcium. Intakes of animal protein were

Table 2 Median (1st, 3rd quartiles) of energy, selected nutrients, dietary fibre, phytate and phytate: $\mathrm{Zn}$ and phytate: Fe molar ratios (per day; per MJ) of subsistence pregnant women $(n=99)$ from Sidama

\begin{tabular}{|c|c|c|}
\hline & $\begin{array}{c}\text { Median (1st, 3rd } \\
\text { quartiles) intakes } \\
\text { per day }\end{array}$ & $\begin{array}{c}\text { Median (1st, 3rd } \\
\text { quartiles) intakes } \\
\text { per MJ }\end{array}$ \\
\hline Adjusted energy* (kJ) & $3981(3156,5211)$ & \\
\hline Utilizable protein† (g) & $15.5(10.4,20.1)$ & $3.8(3.3,4.3)$ \\
\hline Fat $(g)$ & $7.7(4.7,11.7)$ & $2.0(1.5,2.7)$ \\
\hline Carbohydrate (g) & $231.2(178.2,299.7)$ & $57.7(56.4,58.6)$ \\
\hline $\mathrm{Ca}(\mathrm{mg})$ & $479(220,680)$ & $120(59,170)$ \\
\hline $\mathrm{Fe}(\mathrm{mg})$ & $27.1(20.7,33.2)$ & $6.5(6.2,7.4)$ \\
\hline $\mathrm{Zn}(\mathrm{mg})$ & $5.0(3.3,7.2)$ & $1.3(1.1,1.5)$ \\
\hline Ascorbic acid (mg) & $2.2(0.8,4.7)$ & $0.56(0.18,1.3)$ \\
\hline Total dietary fibre $(\mathrm{g})$ & $24.4(15.3,32.8)$ & $6.3(4.7,7.1)$ \\
\hline Phytate (mg) & $1011(528,1575)$ & $253(140,375)$ \\
\hline [Phytate]:[Zn]‡ & $18.6(13.1,23.6)$ & \\
\hline [Phytate]: [Fe]‡ & $3.13(1.73,4.82)$ & \\
\hline
\end{tabular}

*Adjusted for digestibility.

† Adjusted for digestibility and amino acid score. ¥ Molar ratio. very low; less than $1 \%$ of energy intake was provided by dairy products, mainly cow or goat milk, and no cellular animal foods were eaten. As a result, the haem iron content of the diets was zero. The dietary diversity score in Sidama was very low - $75.8 \%$ of the subjects consuming four or fewer types of foods per day.

Estimated energy intakes of these subsistence pregnant women were very low: all the women had adjusted energy intakes below the $\mathrm{FAO}^{18}$ mean energy requirement estimate; 95\% had intakes below two-thirds of this requirement. For zinc, 99\% of the women had inadequate intakes based on the US FNB EAR for zinc (i.e. $\left.9.5 \mathrm{mg} \mathrm{day}^{-1}\right)^{7}$, and all the women (i.e. 100\%) had inadequate zinc intakes when the IZiNCG EAR cutoff of $12 \mathrm{mg} \mathrm{day}^{-1}$ was used ${ }^{1}$. The latter EAR cutoff was selected, based on our analysed median phytate: $\mathrm{Zn}$ molar ratio of the diet (i.e. 18.6) (Table 2). The prevalence of inadequate intakes of protein and calcium was $100 \%$ and $74 \%$, respectively, based on the EARs compiled by Bunch and Murphy ${ }^{17}$ from the corresponding requirements for pregnancy set by international agencies ${ }^{19,27}$. In marked contrast, relatively few women (i.e. 4\%) were at risk of inadequate intakes of iron, using the EAR for iron set by the US FNB (i.e. $\left.22 \mathrm{mg} \mathrm{day}^{-1}\right)^{7}$.

\section{Prevalence of low biochemical measures of zinc, iron and protein status}

Table 4 presents the proportion of women with low biochemical indices of zinc, iron (in the absence of infection/inflammation) and protein status. Of the three nutrients, the estimated prevalence of low biochemical status was highest for protein, followed by zinc; iron deficiency anaemia (based on a low haemoglobin and low plasma ferritin) had the lowest prevalence (8.7\%).

\section{Discussion}

The zinc intakes of the pregnant women of this study were very low, and below those reported in many other developing countries, including other countries in Africa $^{28-30}$. Low energy intakes were partly responsible for these low zinc intakes; as one might expect, energy and zinc intakes were positively correlated $(r=0.86$; $P<0.001)$. Another contributing factor was the relatively high proportion of energy $(\sim 32 \%)$ provided by enset

Table 3 Mean percentage of energy, protein and zinc intakes provided by eight major food groups for subsistence pregnant women $(n=99)$ from Sidama

\begin{tabular}{|c|c|c|c|c|c|c|c|c|}
\hline & Cereals & Enset foods & Legumes & Dairy & Vegetables & Fruit & Oil & Beverages \\
\hline Energy & 58.7 & 29.7 & 3.9 & 0.4 & 3.3 & 0.1 & 0.2 & 3.2 \\
\hline Protein & 56.7 & 11.9 & 10.5 & 1.6 & 11.8 & 0.0 & 0.0 & 7.4 \\
\hline Zinc & 70.2 & 13.3 & 6.9 & 1.0 & 8.1 & 0.0 & 0.0 & 0.5 \\
\hline Iron & 48.6 & 33.5 & 2.8 & 0.1 & 11.1 & 0.1 & 0.0 & 3.9 \\
\hline Calcium & 9.2 & 47.4 & 2.8 & 2.9 & 28.6 & 0.1 & 0.0 & 8.4 \\
\hline
\end{tabular}


Table 4 Prevalence of low measures of zinc, iron and protein for subsistence pregnant women from Sidama

\begin{tabular}{lcc}
\hline Measure & $\begin{array}{c}\text { Number of } \\
\text { subjects }\end{array}$ & $\begin{array}{c}\text { Prevalence of low } \\
\text { values }(\%)^{*}\end{array}$ \\
\hline Plasma $\mathrm{Zn}<7.6 \mu \mathrm{moll}^{-1}$ & 94 & 71.7 \\
Haemoglobin $<110 \mathrm{gl}^{-1}$ & 93 & 19.2 \\
Plasma ferritin $<12 \mu \mathrm{g} \mathrm{I}^{-1}$ & 95 & 32.3 \\
Haemoglobin $<110 \mathrm{gl}^{-1}$ and & 93 & 8.5 \\
$\quad$ ferritin $<12 \mu \mathrm{gl}^{-1}$ & & 90.9 \\
Plasma albumin $<32 \mathrm{gl}^{-1}$ & 95 & \\
\hline
\end{tabular}

${ }^{*}$ In absence of plasma CRP $\geq 5 \mathrm{mgl}^{-1}$.

products with a very low zinc content (Table 3). Of these enset products, kocho - the fermented pulp of enset baked into bread - was most frequently eaten, followed by bulla (white low-fibre desiccated juice from enset pulp) $)^{31}$. Analysis of samples of fermented kocho and bulla consumed by these women revealed a zinc content

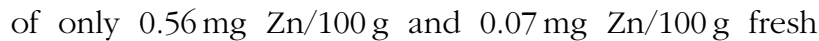
weight, respectively ${ }^{16}$. Measurements of the quantity of zinc absorbed in a convenience sub-sample of this population $^{21}$ demonstrated not only that dietary requirements for zinc were unmet but also that the quantity of zinc absorbed was notably short of physiological requirements. This applied to the less-demanding figure for physiological requirements in late pregnancy of $\mathrm{IZiNCG}^{1}$ as well as to the figure of the US $\mathrm{FNB}^{7}$.

The presence of such low zinc intakes is likely to be further exacerbated by the moderately high phytate: $\mathrm{Zn}$ molar ratios of the diets of the Sidama households in Southern Ethiopia. This arose because unleavened maize bread, followed by enset starchy foods, were the primary and secondary sources of zinc (Table 3). However, fractional absorption of zinc in a convenience sub-sample of this population ${ }^{21}$ was a little higher than that predicted by two models ${ }^{1,32}$ for the ingested level of zinc and phytate. Even higher phytate : $\mathrm{Zn}$ molar ratios have been reported for the diets of pregnant women consuming unrefined maize-based diets in Malawi ${ }^{33,34}$, Nigeria ${ }^{30}$ and Guatemala ${ }^{35}$. It should be noted that in our zinc absorption study $^{21}$, the phytate effect in inhibiting zinc absorption was not as severe as predicted from published models ${ }^{1,32}$. Understanding of this deviation from the predicted effect will depend on further, more extensive research.

It is noteworthy that these Ethiopian pregnant women had even lower intakes of animal-source foods than those reported during pregnancy in many other developing countries $^{28,30,36}$. Such low intakes of animal protein are likely to be an additional factor compromising zinc (and non-haem iron) absorption in the diets of Sidama households in Southern Ethiopia ${ }^{37}$. Small amounts of cow's milk or goat's milk with coffee were the only source of animal protein consumed, and provided less than $1 \%$ of the total energy of the diet (Table 3) compared with about $5 \%$ in rural Malawi ${ }^{28}$. This is surprising because most of the households surveyed owned some livestock, notably goats, cows and chickens. However, they were used mainly as an income-generating activity rather than for home consumption. Further, although the villages were close to Lake Awassa, fish was rarely consumed. Small indigenous fish sources are potentially a rich source of protein and several other nutrients, including calcium and retinol, if eaten whole with bones, and after drying can be powdered and used to enrich porridges based on enset or maize.

In view of the very low zinc intake in association with moderately poor availability that characterises these diets, it is not surprising that there was a high prevalence of inadequate zinc intakes among these women, irrespective of the EAR applied. Indeed, the prevalence estimate appears the highest reported for pregnant women in developing countries to date 28,36 , and somewhat higher than the prevalence of low plasma zinc concentrations noted among this population (i.e. 72\%) (Table 4). The uncertainty associated with the cutoff for serum zinc concentrations during the third trimester of pregnancy may be partly responsible for this discrepancy. The sample size for pregnant women in the US National Health and Nutrition Examination Survey II data used to establish the lower cutoff for serum zinc concentrations for each trimester of pregnancy was very small (i.e. $n=61$ ), limiting the reliability of the 2.5 th percentile estimate $^{1,38}$.

Unlike zinc, the prevalence of inadequate intake of calcium among these pregnant women from Sidama, Southern Ethiopia, was lower than estimates from several other developing countries ${ }^{28,36}$, except for those countries where calcium is ingested from tortillas prepared from lime-soaked maize $\mathrm{e}^{35}$. Both enset and kale, regular components of these diets, have a relatively high content of calcium, which is probably readily absorbed because neither of these plant-based foods is high in phytates or oxalates, known to inhibit calcium absorption $^{39}$. Nevertheless, it is unlikely that the calcium levels in the diets of these Sidama households are high enough to exacerbate the inhibitory effect of phytate on zinc absorption ${ }^{37}$.

It is of interest that, in contrast to zinc, very few of the women were at risk to inadequate intakes of iron, even though iron and zinc usually have a similar distribution in the food supply and are affected by many of the same dietary absorption modifiers ${ }^{12}$. The high content of iron in Ethiopian diets has been emphasised earlier ${ }^{40,41}$ and attributed to the consumption of the indigenous cereal teff (E. teff), oleaginous seeds and Ethiopian kale (B. carinata braun), all foods that appear to contain relatively high levels of iron ${ }^{13,14,42}$. In these Sidama households, however, cereals, notably unrefined high-phytate cornbread, contributed to almost $50 \%$ of the dietary iron, followed by starchy enset products (34\%); vegetables, predominantly kale, provided only $11 \%$ of the total dietary iron (Table 3). 
Some investigators have linked the high iron intakes by population groups in Ethiopia to contaminant iron from soil rather than to iron intrinsic to food ${ }^{40,43}$. The highly variable iron content of samples of fermented kocho consumed by these pregnant women and analysed in our laboratory ${ }^{16}$, and the preparation of kocho by fermenting enset pulp in earth pits ${ }^{31,44}$, both support this suggestion.

Whether contaminant iron joins the common nonhaem iron pool (i.e. is exchangeable) and is thus available for absorption has not been firmly established because predicting the exchangeability of contaminant iron is difficult ${ }^{45}$. Very few of the study participants ( $\sim 8 \%)$ had any evidence of iron deficiency anaemia in later pregnancy, and only about one-third had depleted iron stores (Table 4), even though supplements of iron-folate were rarely consumed by pregnant women in these three villages. Several other reports have indicated that nutritional iron deficiency is not a serious problem in Ethiopia, even during pregnancy when iron requirements are high ${ }^{41}$.

Our findings show a reasonable concordance between dietary and biochemical measures of iron inadequacy among this group of pregnant Ethiopian women, given that the EAR used assumed 25\% absorption of iron. Whether the absence of nutritional iron deficiency can be attributed to up-regulation of iron absorption in late pregnancy in response to the increased demand, or because at least some of these women had sufficient iron stores when entering pregnancy to maintain an adequate iron balance, is uncertain. We used the EAR for iron set by the US FNB (i.e. $\left.22 \mathrm{mg} \mathrm{day}^{-1}\right)^{7}$ to calculate the risk of dietary iron inadequacy in this study because $\mathrm{FAO}^{27}$ did not set an EAR. The US FNB figure for iron absorption during the third trimester of pregnancy (i.e. 25\%) may be unrealistically high, given that these Southern Ethiopian diets contain moderately high levels of phytate and probably polyphenols (from the consumption of coffee), are devoid of haem iron and contain low levels of ascorbic acid (Table 2).

The low energy intakes reported here are consistent with the very low mean body mass index of these women during the third trimester of pregnancy (Table 1), suggesting that such low energy intakes are unlikely to be associated with energy underreporting ${ }^{46}$. Indeed, almost all of the women admitted that they only sometimes or rarely had enough to eat (Table 1). Moreover, anecdotal reports indicate that pregnant women in Ethiopia may restrict their energy intake during late pregnancy in an effort to reduce risk of complications during delivery. Certainly, because of their short stature (mean HAZ = -1.48) (Table 1), these women were likely to be at increased risk during delivery as a result of cephalo-pelvic disproportions ${ }^{47}$. Height below $148 \mathrm{~cm}$ has also been associated with poor foetal outcomes, and in this study $11.1 \%$ of the women had a height below $148 \mathrm{~cm}^{48}$.
It is possible that such low energy intakes may have a negative effect on protein utilisation ${ }^{20}$. If so, the estimate for risk of inadequate protein intakes may be even higher than $95 \%$. Of the women in this study, 91\% had low serum albumin concentrations (in the absence of infection), a proportion consistent with that based on the dietary intakes.

We believe this study has several strengths. The collection of weighed food intakes and samples of staple foods as consumed in the households for chemical analysis enhanced both the accuracy of the portion size estimates and the quality of our food composition data for zinc, iron, calcium and phytate. Moreover, our prevalence estimates for nutrient inadequacies were derived from the distribution of usual intakes. Such estimates were reasonably consistent with those based on biomarkers for zinc, iron and protein status.

We recognise that our results are not based on a representative sample of pregnant women in the third trimester living in the Sidama zone of Ethiopia. Nevertheless, several of the nutritional status variables for these Sidama women were comparable to those reported for the same region in the 2006 Ethiopian Demographic and Health Survey (DHS) (i.e. Southern Nations, Nationalities, and Peoples $(\mathrm{SNNP}))^{49}$. For example, in the SNNP region, both the mean height of women aged 15-49 years and the proportion with height $<145 \mathrm{~cm}$ were very comparable to those reported here $(156.3$ vs. $154.8 \mathrm{~cm} ; 4.1 \%$ vs. $4 \%$, respectively). Further, in the SNNP region, $23.5 \%$ of women had anaemia, defined as a haemoglobin $\leq 110 \mathrm{gl}^{-1}$, compared with $19.2 \%$ in this study. Of the anaemic women in the SNNP region, $14.8 \%, 7.7 \%$ and $10 \%$ were classified with mild, moderate or severe anaemia vs. 13\%, 7\% and $0 \%$, respectively, in our study. Consumption of iron-rich foods in the SNNP region was among the lowest in the Ethiopia DHS survey with $7.9 \%$ of women aged 15-49 years compared with 27.3\% in Addis Ababa consuming iron-rich foods. In our study, none of the pregnant women had consumed iron-rich foods on the weighed record day.

In summary, this study has highlighted for the first time the very low zinc status of these Sidama pregnant women who consumed diets in which almost a third of the energy was derived from enset (E. ventricosum). The latter is a plant-based staple unique to Ethiopia and consumed by more than $20 \%$ of the population ${ }^{31}$. This finding is important, because in the past only the low protein content of enset-based diets has been emphasised. Clearly, a public health intervention is urgently required that addresses simultaneously the coexisting energy and nutrient deficits noted here. A possible strategy includes improving overall dietary quality through enhancing intakes of cellular animal protein, an excellent source of high-quality protein, readily available zinc, iron, vitamin $\mathrm{B}_{12}$ and, in some cases, vitamin $\mathrm{A}$ and calcium. However, to change attitudes and awareness among 
households in this setting about the nutritional benefits of animal-source foods, nutrition education based on formative research must be included as an integral part of any food-based intervention.

\section{Acknowledgements}

Sources of funding: This research was supported by National Institutes of Health grants \#MM01 and \#R21TW006729 (Fogarty International Center and Office of Dietary Supplements), and by a University of Otago Research Grant.

Conflict of interest: None of the authors has any conflict of interest.

Authorship responsibilities: R.S.G. wrote the manuscript with input from other authors. K.M.H., N.F.K., B.J.S., Y.A. and R.S.G. developed the study hypothesis and secured the funding, and Y.A. and A.B. were the project field CO-ordinators. Haematology was performed by I.A. and A.T., biochemical analyses by J.E.W., and food analyses by K.B.B. The following participated in the collection, analyses and/or interpretation of the data. K.M.H., B.J.S., Y.A., A.B., R.S.G., N.F.K., I.A. and A.T.

Acknowledgements: Special thanks to the people of the communities, our team of dedicated research assistants, Keneni Fufa (Laboratory Coordinator, the Bushulo Health Centre) and the laboratory technicans for their technical assistance.

\section{References}

1 Hotz C, Brown KM. Assessment of the risk of zinc deficiency in populations and options for its control. Food and Nutrition Bulletin 2004; 25: S95-203.

2 Sunanda L, Sumathi S, Venkatasubbaiah V. Relationship between soil zinc, dietary zinc and zinc nutritional status of humans. Plant Foods for Human Nutrition 1995; 48: 201-7.

3 Alloway BJ. Zinc in Soils and Crop Nutrition. Brussels: International Zinc Association, 2004.

4 Oberleas D, Harland BF. Phytate content of foods: effect on dietary zinc bioavailability. Journal of the American Dietetic Association 1981; 79: 433-6.

5 Iqbal TH, Lewis KO, Cooper BT. Phytase activity in the human and rat small intestine. Gut 1994; 35: 1233-6.

6 Gibson RS, Perlas L, Hotz C. Improving the bioavailability of nutrients in plant foods at the household level. British Journal of Nutrition 2006; 65: 160-8.

7 Institute of Medicine. Dietary Reference Intakes for Vitamin A, Vitamin K, Boron, Chromium, Copper, Iodine, Iron, Manganese, Molybdenum, Nickel, Silicon, Vanadium, and Zinc. Food and Nutrition Board, Washington, DC: National Academy Press, 2001.

8 Tamura T, Goldenberg RL. Zinc nutriture and pregnancy outcome. Nutrition Research 1996; 16: 139-81.

9 King JC. Determinants of maternal zinc status during pregnancy. American Journal of Clinical Nutrition 2000; 71: $1334 \mathrm{~S}-43 \mathrm{~S}$

10 Castillo-Durán C, Weisstaub G. Zinc supplementation and growth of the fetus and low birthweight infant. Journal of Nutrition 2003; 33: 1494S-7S.
11 Lohman TG, Roche AF, Martorell R, eds. Anthropometric Standardization Reference Manual. Champagne, IL: Human Kinetics Books, 1988.

12 Gibson RS, Ferguson EL. An Interactive 24-h Recall Method for Assessing Intakes of Iron and Zinc in Developing Countries. Washington, DC: ILSI Press, 1999.

13 Ethiopian Nutrition Institute (ENI). Food Composition Table for use in Ethiopia. Part III. 1968-1997. Addis Ababa, Ethiopia: ENI, 1981

14 Ethiopian Health and Nutrition Research Unit (EHNRI). Food Composition Table for use in Ethiopia. Part IV. 1995-1997. Addis Ababa, Ethiopia: EHNRI/Food Agriculture Organization, 1998.

15 Umeta M, West CE, Fufa H. Content of zinc, iron, calcium and their absorption inhibitors in foods commonly consumed in Ethiopia. Journal of Food Composition and Analysis 2005; 18: 803-17.

16 Abeba Y, Bugale A, Hambidge KM, Stoecker BJ, Bailey K, Gibson RS. Phytate, zinc, iron and calcium content of selected raw and prepared foods consumed in rural Sidama, Southern Ethiopia, and implications for bioavailability. Journal of Food Composition and Analysis 2007; 20: 161-8.

17 Bunch S, Murphy SP. User's Guide to the Operation of the World Food Dietary Assessment System, Version 2.0. Berkeley, CA: Office of Technology Licensing, University of California, 1997.

18 Food and Agriculture Organization/World Health Organization/United Nations University (FAO/WHO/UNU). Human Energy Requirements. Report of a Joint FAO/WHO/UNU Expert Consultation. FAO Food and Nutrition Technical Report Series 1. Rome: FAO/WHO/UNU, 2004

19 Food and Agriculture Organization/World Health Organization/United Nations University (FAO/WHO/UNU). Energy and Protein Requirements. WHO Technical Report Series No. 724. Geneva: WHO, 1985.

20 Beaton GH, Calloway DH, Murphy SP. Estimated protein intakes of toddlers: predicted prevalence of inadequate intakes in village populations in Egypt, Kenya, and Mexico. American Journal of Clinical Nutrition 1992; 55: 902-11.

21 Hambidge KM, Abebe Y, Gibson RS, Westcott JE, Miller LV, Lei $\mathrm{S}$, et al. Zinc absorption during late pregnancy in rural Southern Ethiopia. American Journal of Clinical Nutrition 2006; 84: 1102-6.

22 Thurnham DI, Mburu ASW, Mwaniki DL, De Wagt A. Micronutrients in childhood and the influence of subclinical inflammation. Proceedings of the Nutrition Society 2005; 64: 502-9.

23 Stoltzfus RJ, Dreyfuss ML. Guidelines for the Use of Iron Supplements to Prevent and Treat Iron Deficiency Anemia. Washington, DC: International Nutritional Anemia Consultative Group/World Health Organization/United Nations Children's Fund, 1998.

24 Looker AC, Dallman PR, Carroll MD, Gunter EW, Johnson CL. Prevalence of iron deficiency in the United States. Journal of the American Medical Association 1997; 277: 973-6.

25 Nusser SM, Carriquiry AL, Dodd KW, Fuller WA. A semiparametric transformation approach to estimating usual daily intake distributions. Journal of the American Statistical Association 1996; 91: 1440-9.

26 Carriquiry A. Assessing the prevalence of nutrient inadequacy. Public Health Nutrition 1999; 2: 23-33.

27 Food and Agriculture Organization/World Health Organization (FAO/WHO). Human Vitamin and Mineral Requirements. Rome: Food and Nutrition Division, FAO, 2002.

28 Gibson RS, Huddle JMC. Suboptimal zinc status in pregnant Malawian women: its association with low intakes of poorly available zinc, frequent reproductive cycling and malaria. American Journal of Clinical Nutrition 1998; 67: 702-9. 
29 Mostert D, Steyn NP, Temple NJ, Olwagen R. Dietary intake of pregnant women and their infants in a poor black South African community. Curationis 2005; 28: 12-19.

30 Oguntona CR, Akinyele IO. Food and nutrient intakes by pregnant Nigerian adolescents during the third trimester. Nutrition 2002; 18: 673-9.

31 Brandt SA, Spring A, Hiebsch C, McCabe JT, Tabogie E, Diro M, et al. The Tree against Hunger. Enset-based Agricultural Systems in Ethiopia. American Association for the Advancement of Science with Awassa Agricultural Research Center, Kyoto University Center for African Area Studies and University of Florida. Washington, DC: American Association for the Advancement of Science, 1997.

32 Miller LV, Krebs NF, Hambidge KM. A mathematical model of zinc absorption in humans as a function of dietary zinc and phytate. Journal of Nutrition 2007; 137: 135-41.

33 Ferguson EL, Gadowsky SL, Huddle J-M, Cullinan TR, Lehrfeld J, Gibson RS. An interactive 24-h recall technique for assessing the adequacy of trace mineral intakes of rural Malawian women; its advantages and limitations. European Journal of Clinical Nutrition 1995; 49: 565-78.

34 Huddle J-M, Gibson RS, Cullinan TR. Is zinc a limiting nutrient in the diets of rural pregnant Malawian women? British Journal of Nutrition 1998; 79: 257-65.

35 Fitzgerald S, Gibson RS, Portocarrero L, Quan de Serrano J, Vasquez A, Zepeda E, et al. Trace element intakes and dietary phytate/Zn and [phytate][Ca]/Zn millimolar ratios of peri-urban Guatemalan women during the third trimester of pregnancy. American Journal of Clinical Nutrition 1993; 57: 195-201.

36 Sacco LM, Caulfield LE, Zavaleta N, Retamoza L. Dietary pattern and usual nutrient intakes of Peruvian women during pregnancy. European Journal of Clinical Nutrition 2003; 57: 1492-7.

37 Lönnerdal B. Dietary factors influencing zinc absorption. Journal of Nutrition 2000; 130: 1378S-83S.

38 Hotz C, Peerson JM, Brown KH. Suggested lower cutoffs of serum zinc concentrations for assessing zinc status: reanalysis of the second National Health and Nutrition
Examination Survey data (1976-1980). American Journal of Clinical Nutrition 2003; 78: 756-64.

39 Weaver CM, Proulx WR, Heaney R. Choices for achieving adequate dietary calcium with a vegetarian diet. American Journal of Clinical Nutrition 1999; 70: 543S-8S.

40 Hofvander Y. Hematological investigations in Ethiopia, with special reference to a high iron intake. Acta Medica Scandinavica. Supplementum 1968; 494: 1-74.

41 Gebre-Medhin M, Killander A, Vahlquist B, Wuhib E. Rarity of anemia in pregnancy in Ethiopia. Scandinavian Journal of Haematology 1976; 16: 168-75.

42 Wolde-Gebriel Z, West CE, Gebru H, Tadesse A-S, Fisseha T, Gabre $\mathrm{P}$, et al. Inter-relationship between vitamin A, iodine and iron status in school children in Shoa Region, Central Ethiopia. British Journal of Nutrition 1993; 70: 593-607.

43 Hallberg L, Bjorn-Rasmussen E. Measurement of iron absorption from meals contaminated with iron. American Journal of Clinical Nutrition 1981; 34: 2808-15.

44 Pijls LT, Timmer AAM, Wolde-Gebriel Z, West CE. Cultivation, preparation and consumption of enset (Enset ventricosum) in Ethiopia. Journal of the Science of Food and Agriculture 1995; 67: 1-11.

45 Harvey PWJ, Dexter PB, Darnton-Hill I. The impact of consuming iron from non-food sources on status in developing countries. Public Health Nutrition 2000; 3: 375-83.

46 Livingstone $\mathrm{MB}$, Black AE. Markers of the validity of reported energy intake. Journal of Nutrition 2003; 133: 895S-920S.

47 Merchant KM, Villar J, Kestler E. Maternal height and newborn size relative to risk of intrapartum caesarean delivery and prenatal distress. British Journal of Obstetrics and Gynaecology 2001; 108: 689-96.

48 Kelly A, Kevany J, de Onis M, Shah PM. A WHO collaborative study of maternal anthropometry and pregnancy outcomes. Internal Journal of Gynecology and Obstetrics 1996; 53: 219-33.

49 Central Statistical Agency. Ethiopia Demographic and Health Survey. Addis Ababa, Ethiopia and Calverton, MD, USA: Central Statistical Agency and ORC Macro, 2006; 144-62. 